\title{
Modeling and simulation of decision support system analysis of the road transport
}

\section{system in Nigeria}

\author{
Ofut Ogar Tumenayu ${ }^{1}$, Jerome Godwin Egbe ${ }^{2,}{ }^{*}$ and Umoh Enoima Essien ${ }^{3}$ \\ ${ }^{1}$ Department of Computer Science, Cross River University of Technology, Calabar-Nigeria. \\ 2 Department of Civil Engineering, Cross River University of Technology, Calabar-Nigeria. \\ ${ }^{3}$ Department of Computer Science, Cross River University of Technology, Calabar-Nigeria.
}

Publication history: Received on 30 August 2020; revised on 14 September 2020; accepted on 18 September 2020

Article DOI: https://doi.org/10.30574/wjaets.2020.1.1.0011

\begin{abstract}
The complex analysis of traffic system safety in Nigeria based on qualitative and simulation modeling was performed. These models allow us to perform a preliminary assessment of measures aimed at safety improvement of the traffic system situation in Nigeria, and to make projections to improve the parameters of the transport system. In this paper, the results of the system analysis of the transport network safety in Nigeria based on qualitative and simulation modeling are presented. The qualitative model of transport network safety and the model of system dynamics is developed, the safety measures based on simulation are suggested. The obtained results could be used for support of decision making in the field of transport network management in Nigeria. The experiments were conducted on qualitative models, they showed the effect on the transport system parameters of such measures: increasing fines for violations of the road regulations and increasing of the funding of the road repairing and construction. The support organization in decision-making in the management of the urban transport system development is very important. This problem can be solved with the use of different approaches. The use of qualitative and dynamic-system modeling for complex analysis of the transport system and evaluation of measures effectiveness aimed at improving its safety is proposed in this paper.
\end{abstract}

Keywords: Decision; Modeling; Transport system; Road analysis; Simulation

\section{Introduction}

A few tiny and perceptible wellbeing kinds of exploration are completed to upgrade the traffic security plans or road designing arrangements and their execution. In this paper, we are beseeching a methodology utilizing, demonstrating, and reproduction of choice organization investigation for traffic wellbeing measures. The most generally utilized strategies in investigating traffic wellbeing are crash recurrence demonstrating, which may measure exogenous elements adding to the number of car accidents. At the discernible level, crashes from a spatial assortment, (for instance, traffic examination zone or district) are considered to quantify the impacts of monetary and fragment characteristics, transportation solicitations, and association qualities so on give countermeasures from a masterminding perspective. On the contrary hand, minuscule accidents on a section or convergence are broke down to recognize the impact of the mathematical plan [1, 11]. Further, in 1926, the road transport arrangement of Nigeria was characterized into three significant sorts as federal trunk (A) roads, State trunk (B) roads, and neighborhood local government area trunk (C) roads [1]. During thusly, the administrative, local/state, and commonplace/nearby governments got discrete duties regarding the plan, development, and upkeep of roads inside the nation. Even though roads were essentially worked to take care of the railroads and be corresponding to them, streets, in the long run, took over from the rail routes because the nation's road network improved and caught increasingly more traffic from the rail lines, particularly after

\footnotetext{
${ }^{*}$ Corresponding author: Jerome Godwin.Egbe

Department of Civil Engineering, Cross River University of Technology, Calabar-Nigeria. 
independence in 1960. The new roads brought about enormous investment funds in time. Since 1980, the government of Nigeria has extended the Trunk A road network inside the nation significantly $[1,2]$.

A significant element of the current phase of transport improvement in Nigeria is that the advancement of high need linkages, which is identified with an arrangement of 4-lane interstates that were developed inside the nation since 1980. These incorporate the freeways among Lagos and Ibadan, among Shagamu and Benin City, between Benin City and Onitsha, Onitsha, and Enugu likewise as among Enugu and Port-Harcourt through Aba and Umuahia in Southern Nigeria. In Northern Nigeria, another arrangement of the 4-lane interstate has additionally been built among Abuja and Kaduna, among Kaduna and Zaria as among Zaria and Kano, and presently the advancement of a turnpike among Abuja and Lokoja $[1,3]$.

The two-lane interstates decreased time and gave expanded ability to more vehicles to go between the principle urban communities, which they interface together and in this way, more extreme collaboration prompting more financial turn of events. For example, since the improvement of the freeways more extraordinary association is experienced among Lagos and Benin, Port-Harcourt, and Enugu through Aba and Umuahia additionally as between Abuja, Kaduna, Zaria, and Kano and along these lines the proposed Calabar-Ogoja - Benue roadway. Subsequently, the commitments of road transportation to the financial advancement in Nigeria aren't just huge yet additionally unequivocal since they opened new terrains for the agrarian, mechanical, and private turn of events. Roads changed the direction of within zones of the nation from the streams and along these lines the railroads to the street organization and opened within parts of the nation to current methods for transportation since they're adaptable. They opened monetary and repayment boondocks and gave expanded admittance to zones where fare crops were developed. The major inland rivers in Nigeria are the River Niger and River Benue which analyze the nation into east, west, and north segments. The 2 rivers meet at Lokoja in Kogi State. The two waterways ascend outside the nation however around 1440 kilometers of the River Niger and 960 kilometers River Benue of River Benue flow within Nigeria.

In Northern Nigeria, River Sokoto and River Kaduna are a portion of the significant feeders of the River Niger while Gongola River and Katsina-Ala River are a portion of the significant feeders of the River Benue. In North-Eastern Nigeria, the Hadeija River and others river into the Lake Chad [4, 5] and [6]. Other major waterfront waterways in South-Western Nigeria incorporate River Ogun, River Osse, and Oshun River, while the Seaside Rivers in South-Eastern Nigeria incorporate Cross River, Imo River, Aboine (Ebonyi) River, and different feeders of the River Niger, for example, Anambra and Mamu Rivers. As per [6], they arranged different kinds of transportation issues in Nigeria to include: awful roads, significant expense and deficiency of fuel, gridlock in metropolitan territories, the insufficiency of administrations, significant expense, and lack of extra parts, and helpless vehicle support. Essentially, [6,7] set up that country travel and transport in Nigeria stay troublesome because of the helpless state of streets and transport administrations, which have kept on irritating the issue of low efficiency and an elevated level of neediness in rustic regions.

The complex programs of road transport system effectiveness improving are very costly, and the municipal authorities should be confident in the effectiveness of such programnes implementation. This paper aims to provide the needed support for the organization, agencies in tackling the problem of traffic congestion mostly in densely populated cities around the globe that are underdeveloped technologically in decision-making in the management of the urban transport system development, this problem can be solved with the use of different approaches. The use of qualitative and dynamic-system modeling for complex analysis of the transport system and evaluation of the effectiveness of the measures aimed at improving its safety is proposed in this paper.

\section{Research Methodology}

First, we performed pre-analysis in the subject area according to the methodology proposed in [8]. Managing the urban transport system, the municipal authorities should take into account the interests of multiple concerned parties, often with conflicting goals. A list of such parties was formed and their interests intersect using the transport system. According to the result of expert analysis of this list, the main aspects of the transport system their corresponding targets reflecting the different group interests, such as the transport system safety, or the impact upon the environment, social and economic goals, etc.

The tree of goals was created during the analysis; the sets of attributes were marked for each of the tree sub-goals. They describe the transport system with the corresponding point of view. The information sources for the attributes about their values are highlighted, also the possible attribute values are highlighted and the evaluation of these values following the purposes for which the attributes belong. The goals tree fragment and sub-goal attributes description "Improving the security of the transport system" are shown in Figure 1. 


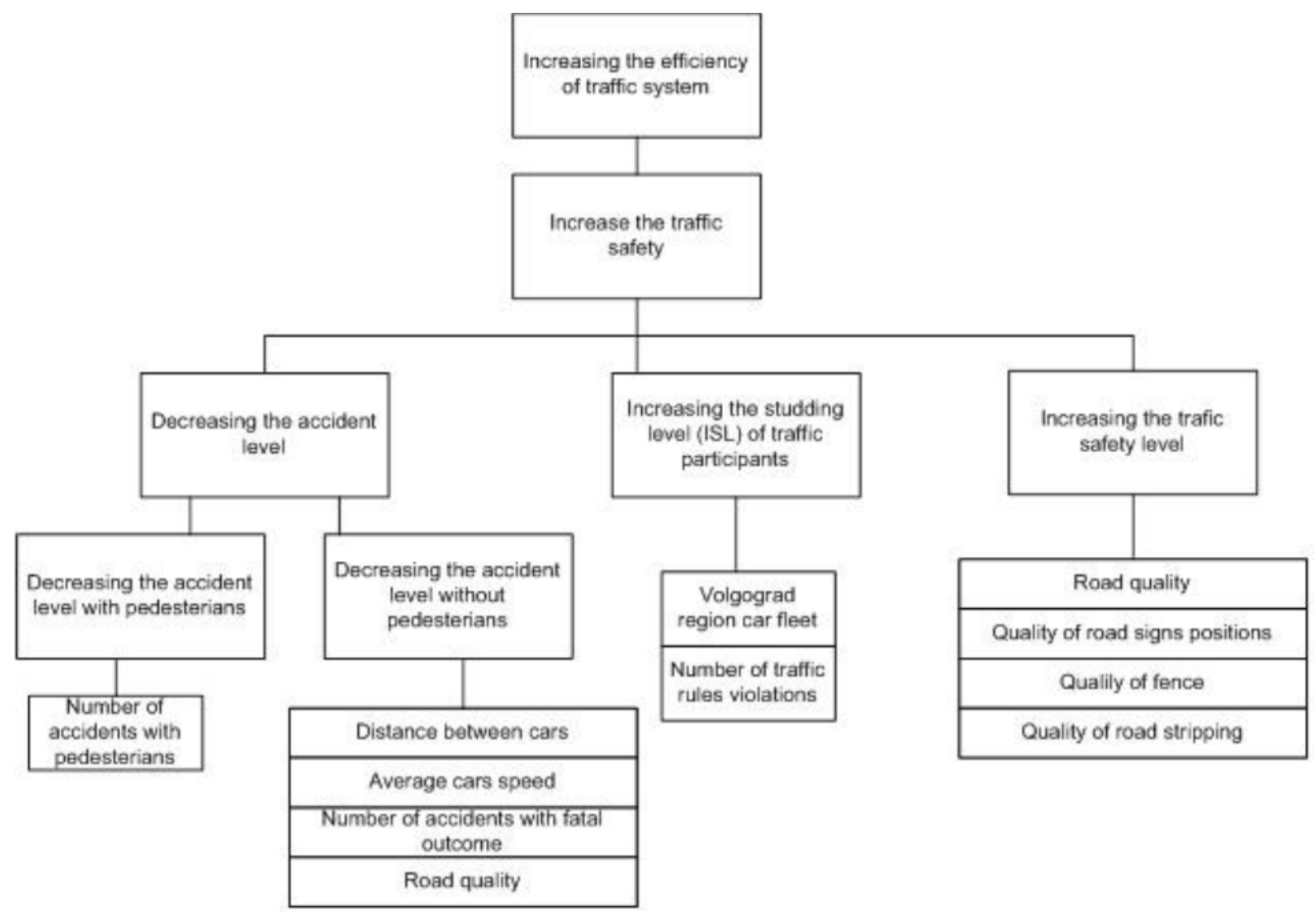

Figure 1 Goals tree fragment [8]

Advanced video pictures permit perceiving vehicle projections with a serious extent of exactness and naturally computing traffic stream boundaries, for example, the number of vehicles, their rates, separations among them, etc [11, 12]. Quadcopters [13] can be utilized for all-encompassing aeronautical video pictures (Figure 1), camcorders on the tops of tall structures can likewise be introduced, or unique pinnacles can be utilized.

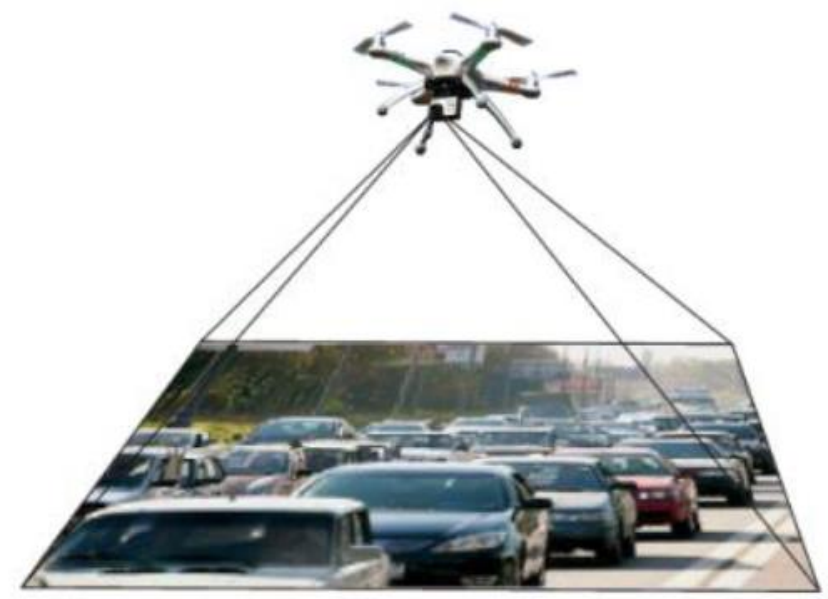

Figure 2 The principle of panoramic video monitoring of traffic flows with using a quadrocopter [13]

According to the analysis result of various programs of transport systems development in Russia [14,15] and [16], uses alternative actions for various attribute values were described. They can be performed for the transport system effectiveness improvement, alternatives description fragment, aimed at the transport system safety improvement is shown in Figure 3. 
World Journal of Advanced Engineering Technology and Sciences, 2020, 01(01), 001-010

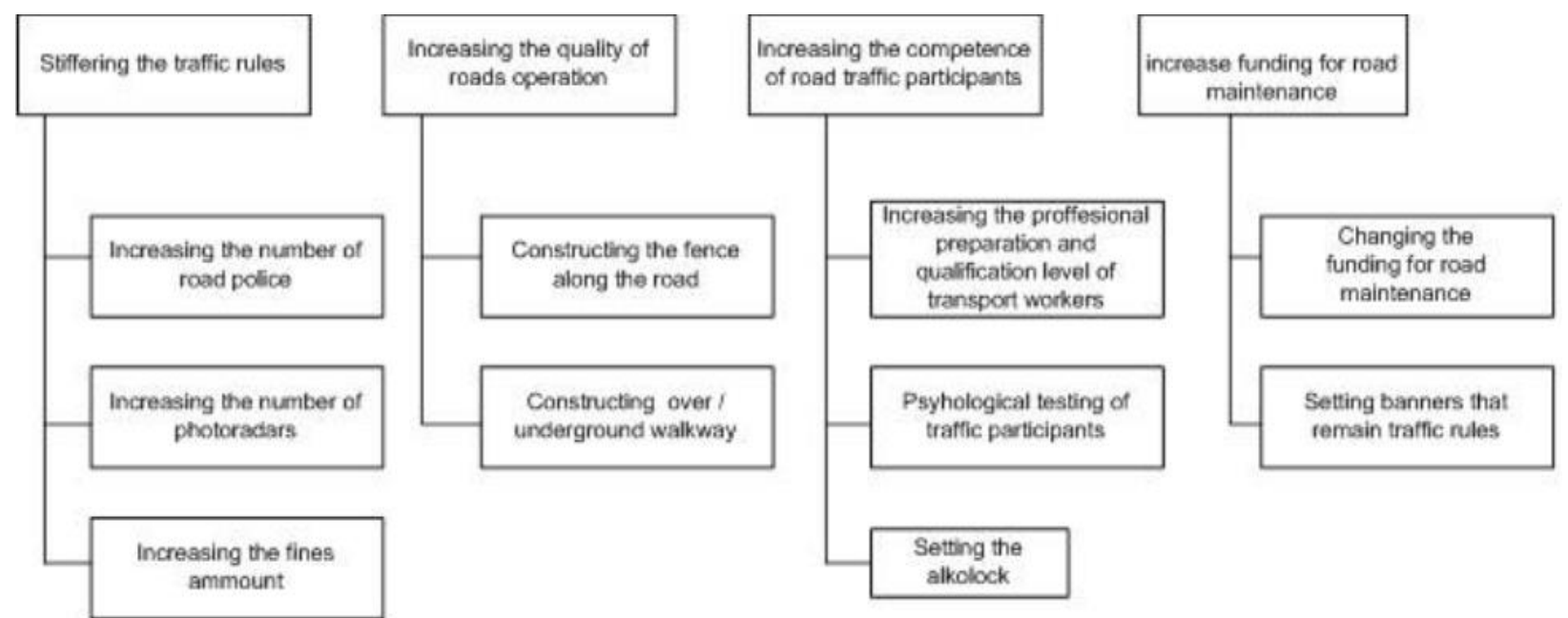

Figure 3 Alternatives description fragment of at the transport system safety improvement

\section{Qualitative modeling of the road transport system}

To establish and explore relationships between the possible alternatives and goal attributes in the quality modeling system by Garp3 [11] a qualitative model of the transport system was developed (QM), which is as follows:

$\mathrm{QM}=\{\mathrm{SSC}, \mathrm{CC}\}$

Where SSC is a set of simple model components; CC - a set of constituent model elements

$\mathrm{SSC}=\{\mathrm{SC}, \mathrm{BC}\}$

Where SC - simple structural components of the model; BC- simple system components defining the system behaviour.

$\mathrm{SC}=\{\mathrm{EE}, \mathrm{SRE}\}$

Where EE - the hierarchy of entities (the hierarchy of entities for the transport system safety model built-in Garp3 is represented in Figure 3), SRE is a set of relations between attributes of the transport system (SRE $=\varnothing$, because attributes on each other are not affected).

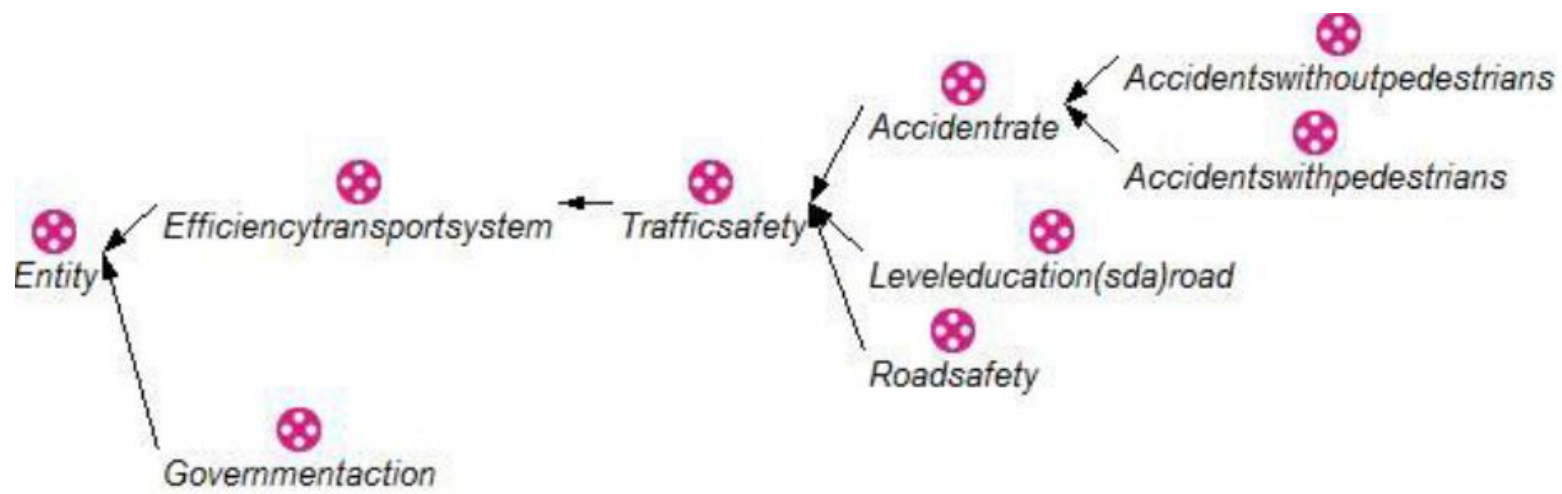

Figure 3 Hierarchy of entities for transport system qualitative model

$B C=\{Q, Q S, D\}$

Where $Q$ is a set of qualitative variables (Eq. (6)); $Q S$ is the space of admissible values

(Eq. (5)); 
$\mathrm{QS}\{\mathrm{Hmz}, \mathrm{Pz}\} \mathrm{Hmz}=\{$ High, Middle, Zero $\} \mathrm{Pz}=\{$ Plus, Zero $\}$

$\mathrm{Q}=\{$ Accidentsinvolvingpedestrians, Averagespeedoftraffic, Countcars, Countoftrafficviolations, Distance, Fatalcrash, Finance, Fine, Qualityinstallationfencing, Qualityofaccomodationofroadsigns, Quality of road markings, Qualityofroadway, Value\}

D is a set of relations of cause and consequence of governmental relations:

$\mathrm{D}=\{1+1-P+P-\}$

Where 1+ and 1- are the positive and negative impact of the one variable value upon another variable, respectively, P+ and $\mathrm{P}$ - are direct and inverse proportionality between the values of the variables respectively.

$\mathrm{CC}=\{\mathrm{SF}, \mathrm{PF}, \mathrm{SC}\}$

Where SF is a set of static fragments of qualitatively model formed from elements of the SSC as depicted in Figure 4; PF is a set of dynamic elements of the qualitative model, formulated Rowan SSC elements see Figure 4; SC is a set of simulation scenarios of a qualitative model, formed from elements of SSC.

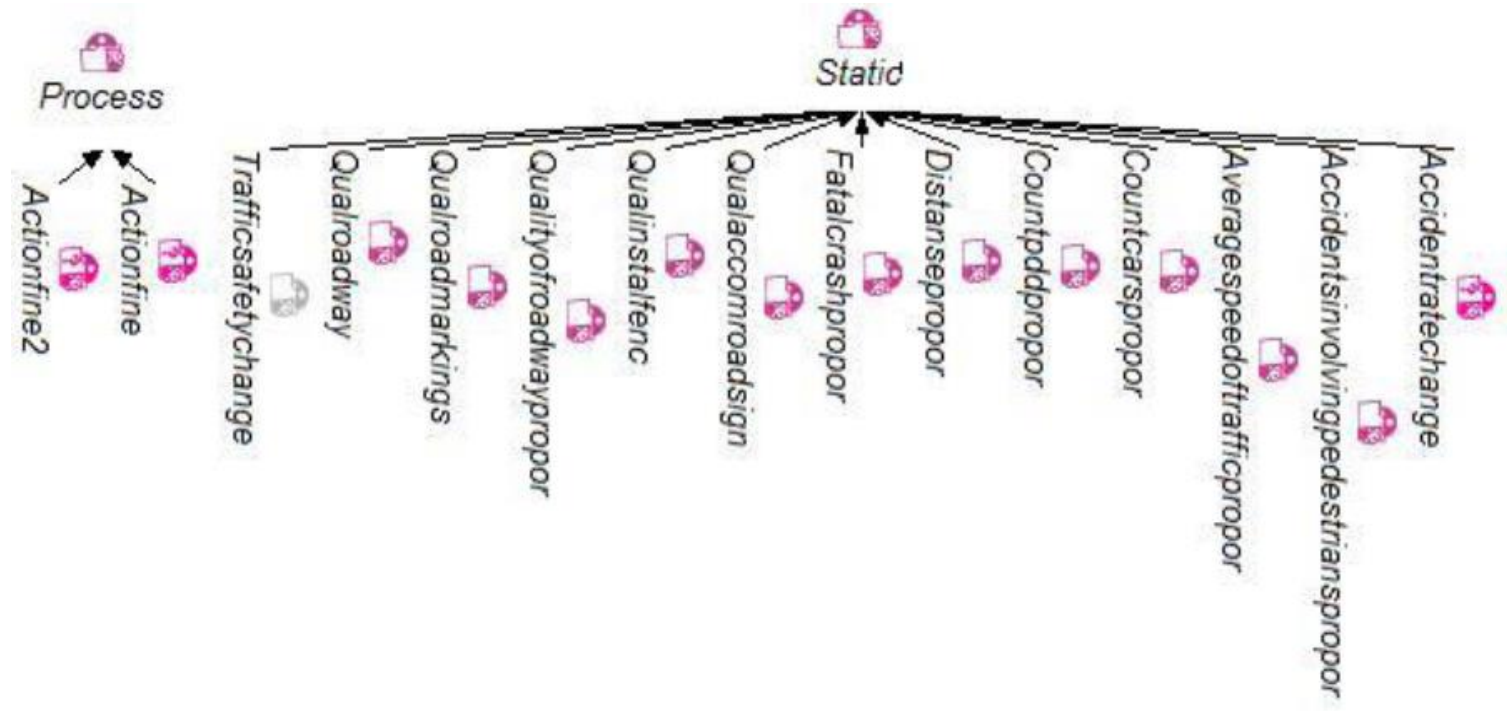

Figure 4 The hierarchy of the static and dynamic model elements

The experiments were conducted on qualitative models, they showed the effect on the transport system parameters of such measures: increasing fines for violations of the road regulations and increasing the funding of the road repairing tand construction. In particular, it was found that the increase of the fines for violations of the road regulations positively impacts on the studding the road regulations by the drivers and the increasing of the funding of the road repairing and construction impact on the road condition in both experiments, the traffic safety and the transport system efficiency increased. Figure 5 shows one of the states resulting from the simulation. 


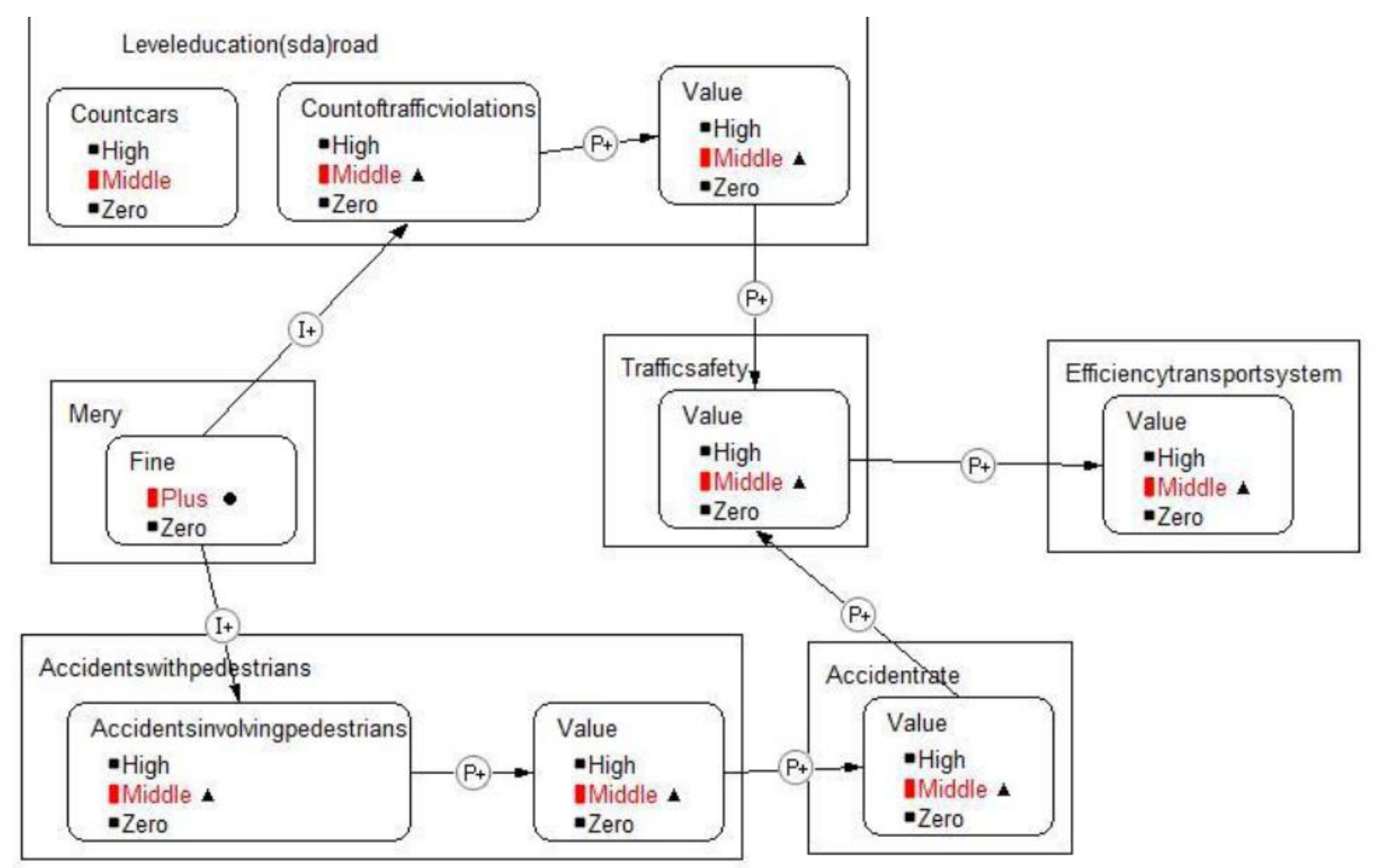

Figure 5 The results of simulation conducted on the qualitative model

\section{Discussion and analysis of the result}

\subsection{System dynamics model of the transport system}

Dynamic-system modeling is actively used for creating programs of the city development $[17,19]$ and $[20]$. This approach allows us not only to stimulate the development of the processes occurring in this system but also to make specific recommendations on improving system management efficiency. The goal of modeling at this stage of study is an approximate analysis of the development dynamics of the city transport system and exploring the possible consequences of decisions taken by its transformation from a security point of view. We used a workbench Vensim 5.0 for the modeling, [Vensim Product Center, http://www.vensim.com/, Last accessed on 022/07/2020].

For a formal description of the system dynamics model, we introduce the following labeling. Denote the variable "time" by " $t$ ", the initial value is equal to zero and each cycle increases it by a sufficiently small positive increment dt. The transport system security is described by the set of equations (element of the formal model):

$\left.\mathrm{STS}=f\left(\frac{(1-A C C)+L D+S H W)}{3}\right)-S T S_{t-1}\right) \mathrm{dt}$

Where STS - road traffic safety, Acc is an accident level, LD is a level of road users training, SHW is the safety of roads;

$\mathrm{ACC}=f\left(\frac{\text { AccPed }+ \text { AccNPed }}{2}-A C C_{t-1}\right) \mathrm{dt}$

Where AccPed is the accident level involving pedestrians, AccNPed is the accident level without pedestrians.

$\mathrm{LD}=\left(\right.$ IF THEN ELSE $\left(\operatorname{countPDD}<\operatorname{countCars} * \frac{1.5}{1000}, \frac{\operatorname{count} P D D}{\operatorname{countCars} * \frac{1.5}{1000}}, 0\right)-L D_{t-1}$

Where CountPDD is a road regulations violations (the number of registered violations in the city period under review), CountCars is the car fleet of Nigeria (the number of heavily used cars), 
$\mathrm{SHW}=f\left(\frac{Q R+Q F+Q M+Q S}{4}-S H W_{T-1-}\right) \mathrm{dt}$

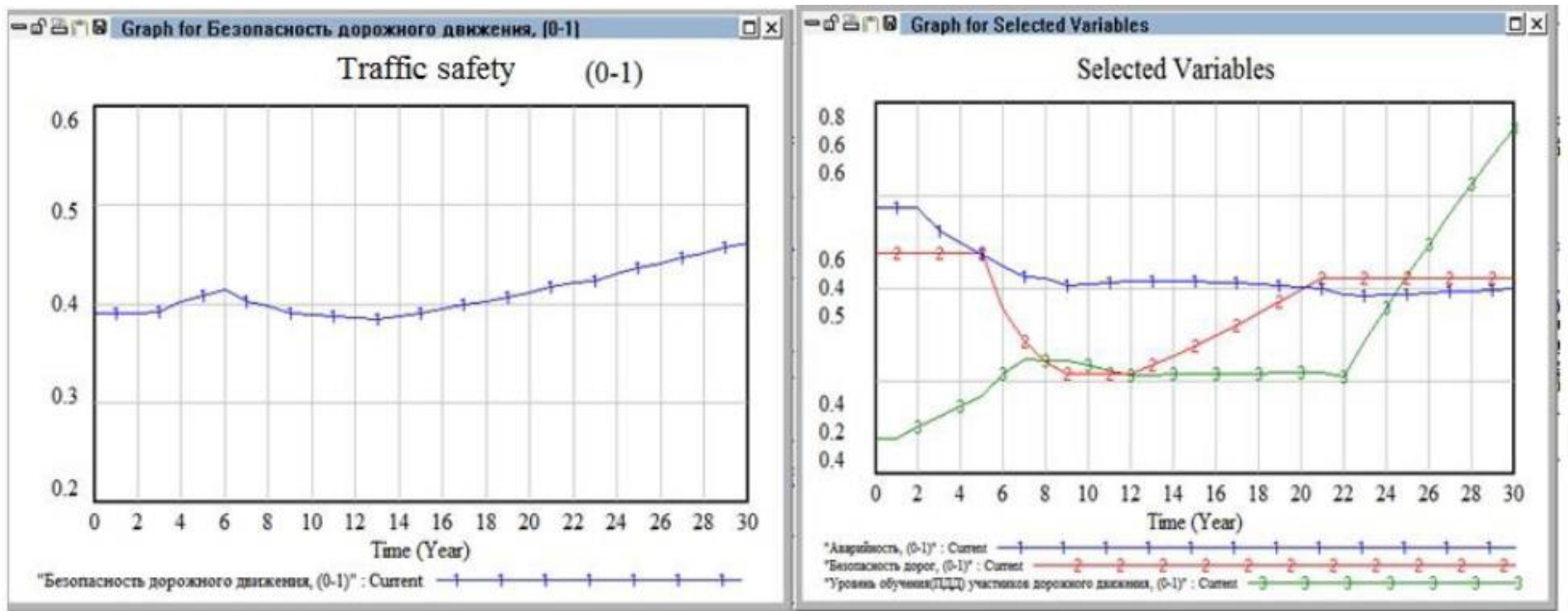

Figure 7 The simulation results based on measures aimed at improving the safety of the transport system

The security level increased by 5\%. From the twentieth to the thirtieth year's fines increase, which increases the level of traffic participants studying, the overall level of security also increases. According to the simulation results, we can conclude that the most effective measures are fines increasing and funding increasing. As a result of over 30 years with the given parameters the safety level increase by about $25 \%$, but the mark of "0.6" ("good") was achieved. Where CountPDD is a road regulations violations (the number of registered violations in the city period under review), CountCars is the car fleet of Nigeria (the number of heavily used cars),

$\mathrm{SHW}=\mathrm{f}\left(\frac{Q R+Q F+Q M+Q S}{4}-S H W_{T-1-}\right) \mathrm{dt}$

Where QR is that the quality of the roadway, QF is that the quality of road fence, QM is that the quality of road signs set. A series of numerical experiments were conducted on the proposed model, to research the dynamics of the processes developed during this system when the parameters affecting safety change. within the first experiment that was performed the modeling of the transport system without changes of safety improvements with the subsequent initial data: simulation time - 30 years, the amount is one year; improving effect is absent, the amount of cars increases per annum $[8,15]$.

As a result, the values of all parameters, including the transport system safety, gradually decreased. Measures aimed toward city transport system improvement were considered during the modeling within the second experiment [14, 16]: from the primary to the fifth year the amount of the patrol increased on 30 pcs, per year, from the tenth to the 20 th year the funding of the transport system development increased per annum, the results are presented in Figure 7. Which is consistent with the results of the second experiment (see Figure 7) we will say, that the traffic safety curve changed considerably.

From the primary to the fifth year, the positive effect of measures like new zebra crossing construction and patrol number increasing improved traffic safety by $10 \%$. From the fifth to the tenth year the best impact produced such factors as the installation of speed breakers, signs and posters reminding the traffic rules, it's a positive effect on the extent of traffic participants studying, but these measures decrease the road safety due to road stripping quality decreasing and therefore the overall road safety decreases. At such the values, and it measures doesn't improve security, therefore, there's no sense to spend money on such measures, and as a result, the most goal isn't achieved. From the tenth to the 20th year, only the funding makes affect. It improves traffic safety greatly since these allocated funds are spent mainly on construction and repairing, the opposite factors vary slightly.

The security level increased by 5\%. From the twentieth to the thirtieth year's fines increase, which increases the level of traffic participants studying, the overall level of security also increases. According to the simulation results, we can conclude that the most effective measures are fines increasing and funding increasing. The security level increased by $5 \%$. From the twentieth to the thirtieth year's fines increase, which increases the level of traffic participants studying, the overall level of security also increases. According to the simulation results, we can conclude that the most effective 
measures are fines increasing and funding increasing. As a result of over 30 years with the given parameters the safety level increase by about $25 \%$, but the mark of " 0.6 " ("good") was achieved.

\section{Conclusion}

From the primary to the fifth year, the positive effect of measures like new zebra crossing construction and patrol number increasing improved traffic safety by $10 \%$. From the fifth to the tenth year the best impact produced such factors as installation of banners, signs, and posters reminding the traffic rules, it's a positive effect on the extent of traffic participants studding, but these measures decrease the road safety due to road stripping quality decreasing and therefore the overall road safety decreases. At such values, this measure doesn't improve security, therefore, there's no sense to spend money for such measure, and as a result, the most goal isn't achieved. From the tenth to the $20^{\text {th }}$ year, only the funding makes an impact. Traffic safety is taken into account as one of the foremost critical problems with transportation. The consistent efforts of state officials and transportation engineers have ensured that fatalities from traffic collisions have gradually declined in Nigeria.

The matter of traffic jams is often identified together of the foremost pressing problems of megacities, especially Nigeria traffic jam is that the main explanation for the residents being late for work and that they impede the work of the emergency services and harm the event of the city's infrastructure. The complex analysis of traffic system safety in Nigeria supported qualitative and simulation modeling was performed. These models allow us to perform a preliminary assessment of measures aimed toward the security improvement of the traffic system and to form projection too enhance the parameters of the transport system. The results are often used for creating a choice within the management of the urban transport system which will allow the event of simpler transport system development.

It's more productive to style the vehicle foundation of the town deliberately (pre-dissect traffic at various seasons, at various times, on open occasions and non-weekend days, top occasions, at that point on). Accordingly, the errand of making a framework for observing traffic streams emerges. The complex programs of road transport system effectiveness improving are very costly, and therefore the municipal authorities should be confident within the effectiveness of such program implementation.

\section{Compliance with ethical standards}

\section{Acknowledgments}

The authors sincerely appreciate the Government of Cross River State, Nigeria for educational partnership with the republic of Russian for inter Country study exchange and their support through counter funding with the government of Cross River State that aided us to carry out the study successfully.

\section{Disclosure of conflict of interest}

The authors have declared that no conflict of interest.

\section{Statement of ethical approval}

'The present research work does not contain any studies performed on animals/humans subjects by any of the authors'.

\section{Statement of informed consent}

The authors have declared that no conflict in the statement of informed consent

\section{References}

[1] Federal Road Safety Commission (FRSC). Planning Advisory Unit Analysis. 2014.

[2] World Health Organization (WHO). Global State Report on Road Safety: Supporting a Decade of Safety (C) World Health Organization. 2013.

[3] Taffee EJ, Morrill RL, Gould PR. Transport Expansion in Underdeveloped Countries: A Comparative Analysis Geographical Review. 1963; 53: 503-529.

[4] Simon D. Transport and Development in the Third World. Routledge, London. 1996. 
[5] Aderamo Aj, Omolaran OI. Accessibility Problem and the Incidence of poverty in Nigerian Rural Environment: A Case of Offa Local Government Area of Kwara State". Geo studies Forum. Publication of the Department of Geography, University of Ilorin. 2006; (3)2: 45-56.

[6] Aderamo AJ, Magaji SA. Rural Transportation and the Distribution of Public Facilities in Nigeria; A Case of Edu Local Government Area of Kwara State". Journal of Human Ecology. 2010; (29)3: 171-179.

[7] Barhotkin VA, EI Minakov, DS Kalistratov, MP Kochetkov. Methods of Artificial Intelligence in the Tasks of Information and Measuring Analysis and Digital Processing of Quasi stationary Aerovideoimages. 2016 International Conference on Actual Problems of Electron Devices Engineering (APEDE).

[8] Agureyev IE, Minakov EI, Kalistratov DS, Kiselev AP, Frolov NA. The method of geometric reconstruction of the asphalt pavement projection in the problems of statistical analysis and compression of aerial video images of traffic flows. Izvestiya of Tula State University. Technical science. 2007; 3: 200-205.

[9] Monitoring of the Megacities Transport Infrastructure. Civil Engineering Journal. 2019; 5(5).

[10] National Highway Traffic Safety Administration. Traffic safety facts 2015. Department of Transportation. 2015.

[11] Cai Qing. Integrating the macroscopic and microscopic traffic safety analysis using hierarchical models. Electronic Theses and Dissertations. 2017.

[12] Dogerty Martin Jr. Drones full illustrative guide to Unmanned Aerial Vehicles, Grand Master. 2017.

[13] Olomola AS. Understanding Poverty in Nigeria: Highlights from NISER Review of Nigerian Development". In NISEREEL, the magazine of the Nigerian Institute of Economic and Social Research, No. 4\&5, December 2003. Ibadan. 2003.

[14] Reichert P, Borsuk M, Hostmann M, Schweizer S, Sporri C, Tockner K, Truffer B. Concepts of decision support for river rehabilitation. Environmental Modeling and Software. 2017; 22: 188-201.

[15] Transport Strategy of the Russian Federation for the period until. 2030.

https://www.ey.com/Publication/vwLUAssets/EY_-

_Infrastructure_in_Russia:_the_road_to_2030/\%24FILE/EY-the-road-to-2030-survey-of-infrastructuredevelopment-in-russia.pdf.Accessed on the 21 of August 2020.

[16] Development of the transport system of Russia. (2010-2015).

https://www.unece.org/fileadmin/DAM/trans/doc/2011/wp5/06 WP5-RF-Presentation-ENG.pdf. Accessed on the 21 of August 2020.

[17] Home: The Qualitative Reasoning and Modelling https://ivi.fnwi.uva.nl/tcs/QRgroup/QRM/links/accessed on the 21 of August 2020.

[18] Sterman J. Business Dynamics. Systems Thinking and Modeling for a Complex World. McGraw-Hill Companies. 2000; 982.

[19] Gary M, Kunc M, Morecroft J, Rockart S. System dynamics and strategy. System Dynamics Review. 2008; 24(4): 407-429.

[20] Sadovnikova NP, Parygin DS, Manunina EV. Quality management of the urban environment using the system dynamics method. Modern scientific research and their practical application, Is. 2013; 4 (J113): 176-182.

\section{Author's short biography}

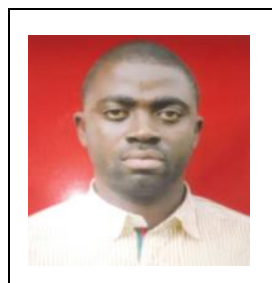

Ofut, Ogar Tumenayu is a lecturer, in the Department of Computer Science, Cross River University of Technology, Calabar-Nigeria. He obtained Masters of Engineering in 2014 from the Volgograd State Technical University, Russian Federation, and is currently studying for his Ph.D. at the University of Nigeria Nsukka. He has a kind interest in research with several publications in reputable Journals including Scopus. 


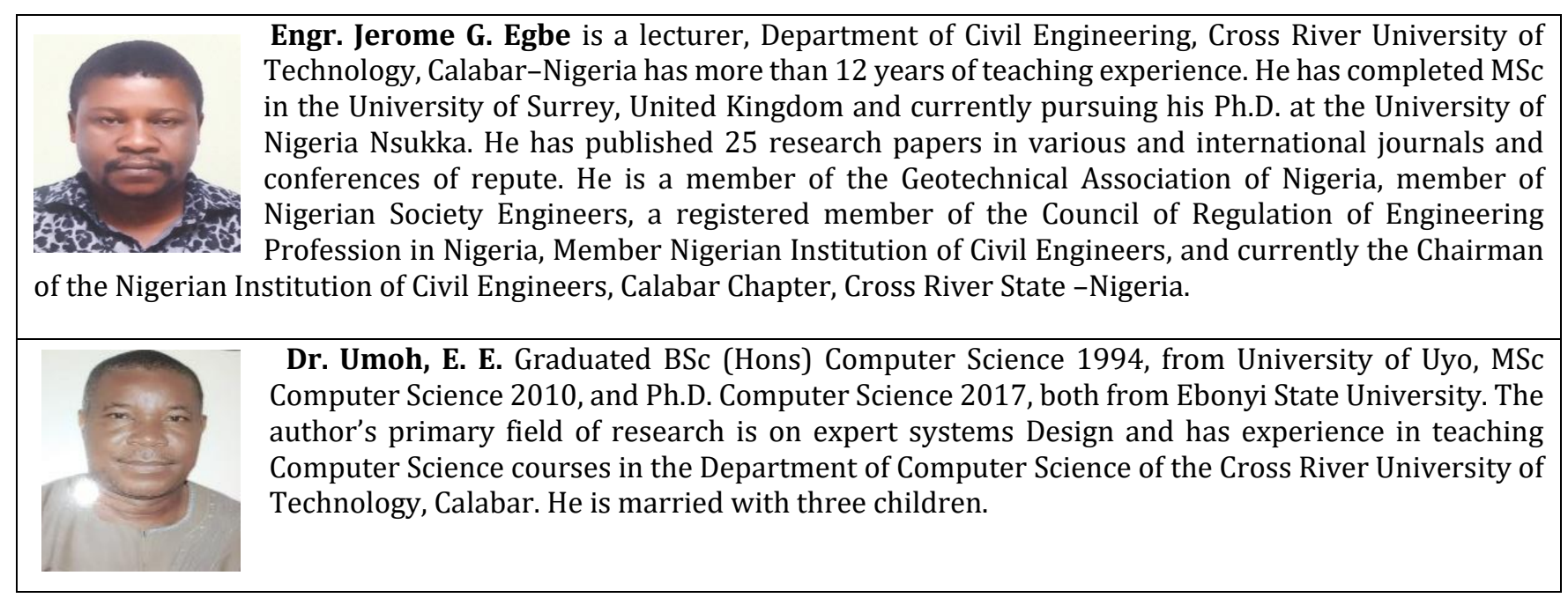

